a recognition of intellectual contribution, equitable distribution of benefits, capacity building and so forth - are not generally considered in this book.

This ethnoflora is set in the purely descriptive and colonial ethnobotanical traditions dating back to Linnaeus and before. Nonetheless, it is most useful for documentation, conservation and development, even if it does not advance the modern science of ethnobotany or reconcile inequities between scientific and traditional knowledge.

Jan Salick is curator of ethnobotany, Missouri

Botanical Garden, Box 299, St Louis,

Missouri 63166-0299, USA.

\section{Reforming research}

\section{Scrutinising Science: The Changing UK Government of Science \\ by Rebecca Boden, Deborah Cox, \\ Maria Nedeva \& Katherine Barker \\ Palgrave: 2004. 218 pp. $£ 45$}

\section{Brian Heap}

The dramatic changes in UK government research establishments (GREs) during the past 20 years constitute one of the most radical experiments in the organization and management of scientific research. And while these changes have been going on, mad-cow disease, foot-and-mouth disease and anthrax have thrust these labs into the public view. At other times, however, their work is less conspicuous but nonetheless highly significant for the public good.

During the 1980s and 1990s, successive Conservative governments seized the opportunity to address the perceived shortcomings of GRE laboratories. The experiment is outlined in the book Scrutinising Science, where it is seen through the lens of social and political science. The authors' analysis is based on interactions with policy-makers, senior managers and administrators tasked with carrying out their paymasters' orders, rather than on the firsthand experience of bench scientists. Some scientists found that the trauma of uncertainty and indecision resulted in planning blight and a loss of morale that was not readily reversed.

The authors helpfully trace the historical origins of the reform of GREs to theories that viewed science as a social institution: governments and politicians were supposed to fund science generously but should not intervene in the affairs of science, nor expect any tangible returns. The research councils that were formed early in the twentieth century existed on the principle of 'research council autonomy' espoused by R. B. Haldane, and other research establishments were created to serve their government departments or ministries directly. In the second half of the twentieth century,

\title{
Secret sex
}

Invisible to the naked eye, pollen grains are tough enough to have survived for millennia and display a wide diversity of forms, fascinating artists and scientists alike. In Pollen: The Hidden Sexuality of Flowers (Papadakis, £35), botanist Madeline Harley and artist Rob Kesseler bring pollen into closer view. The informative text is accompanied by stunning original micrographs of pollen grains, and photographs of the flowers that shed them. The book also includes engravings by previous observers of pollen, including Franz Bauer and Ernst Haeckel.

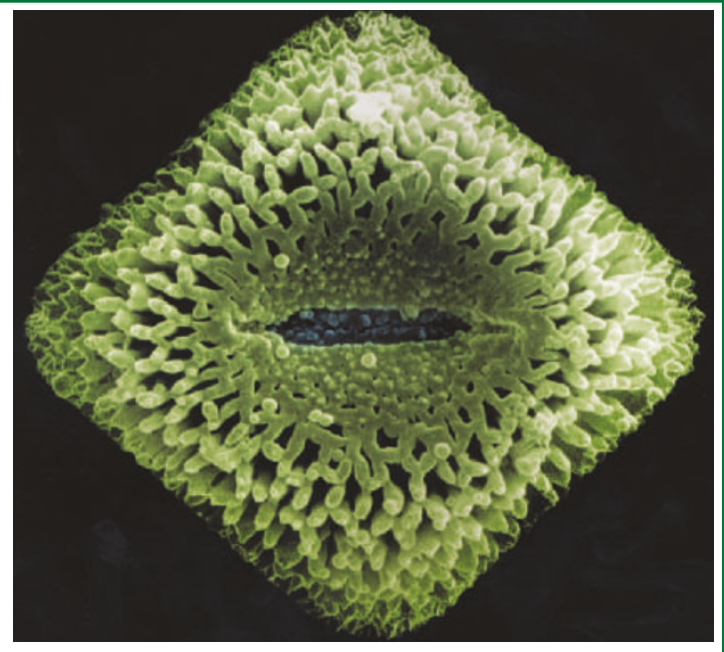

new models of governance and ownership structures appeared, or were imposed upon GREs. These models ensured closer control by departments through measures such as contractor-customer arrangements - part and parcel of making science and technology 'useful' to the departmental customer.

Later, an emerging 'new public management' (NPM) ideology pervaded government policies, driven by the practice of management by accounting. The NPM reform was driven with "breathless urgency" by politicians such as Michael Heseltine, with an outcome typified by complexity and heterogeneity. Eighteen science and technology establishments were transformed into 'next step agencies' between 1989 and 1996, with funding allocated by the contractorcustomer mechanisms; 15 establishments were translated into 'executive agencies' by 1992. The process was suspended in 1997 by the incoming Labour government. The authors conclude that the application of NPM reform to GREs was complicated, messy and driven by opportunism, because GREs were a relatively minor part of government.

What of the present? This complicated picture is addressed by a brief description of individual GREs and their current status. There is also a discussion of eight laboratories that have undergone this transformational organization, including the National Engineering Laboratory, the Laboratory of the Government Chemist, the National Physical Laboratory, the Met Office and the Defence Evaluation and Research Agency. The authors acknowledge that resistance to reform proved problematic in some sectors (the old Ministry of Agriculture, Fisheries and Food "proved itself remarkably adept at avoiding the privatisation issue"), but they discover a sense of relief in some laboratories that found themselves free of the restrictive practices of the past.

The authors are much less sanguine, however, about the long-term impact of reform, in terms of the quality of science, the way that technologies are provided to government, and in particular the transparency of reporting mechanisms and accountability to departments. Accountability to departments is now done in private, based on unpublished contracts - hardly a mechanism to instil confidence in laboratories whose functions are supposed to be transparent and carried out in the national interest.

Turning to the future, the authors express concerns resulting from the earlier policies of an "energetically reforming government" that "decided it could change things everything in fact, including science". The dissolution of GREs that had evolved over a long period of time in response to the government's need for science and technology, the creation of organizations more by accident than design, and the cost to the Exchequer of reforming GREs that were deemed eminently non-marketable - these are topics that the jury will debate for some time.

It would have been informative to evaluate in greater depth the parallel impact of NPM reform on research-council institutions, and the spillover effect in universities, too often portrayed here as remaining, in the words of economist Robert Merton, "a publicgood activity compared to a commercial one". However, this is an important and well researched book, and we should be grateful that it has been written, not least because any government bent on further reform, if it is to bring about beneficial change, would benefit from reading this recent history of the governance of science.

Brian Heap is an honorary fellow, St Edmund's College, University of Cambridge,

Cambridge CB3 OBN, UK.

\section{Erratum}

The Surinam toad that appeared alongside the recent review by David Lodge of George W. Cox's book Alien Species and Evolution (Nature 432, 276-277; 2004) was of the wrong species. The pictured toad (Pipa pipa) resides happily in South America and is not the pest (Bufo marinus) that has been introduced into Australia. Nature apologises for this mistake. 